\title{
Analysis and Assessment of the Regional and Transregional Impacts of Industrial Activities in District 21 of Tehran
}

\section{Mariam OliaeiTorshiz}

\author{
Lecturer of Islamic Azad University of Kashmar, Architecture Department (Corresponding Author)
}

Fatemeh Hashemi Nejad

Research Assistant in Research Center of Jahad University

Vajihe Hedayati

PhD Student in Esfahan University, Geography and Urban Planning Department

Mahin Razavian

Lecturer in Paayam Noor University of Shahrood, Geography and Urban Planning Department

Doi:10.5901/ajis.2016.v5n3s1p460

\section{Abstract}

Air pollution is an offspring of industrial development exacerbated by population growth and urbanization. Nowadays, this has turned out to be one of the major problems of metropolitans. Being the most populated city of Iran, having specific geographical features, and being home to more than $\% 20$ of all Iranian industries, Tehran also suffers from air pollution. Many of these factories are located in district 21 of Tehran where 1391.9 hectares (27 percent) of the area is allocated to industries making it a congruent subject for the present study. This study aims to analyze and assess regional and transregional impacts of industrial activities in district 21 of Tehran. Research methodology of the study was analytic-evaluative (content analysis_case study). Data analysis was performed using the IHWP fuzzy model. In the first part of the present study 8 indices such as air, water, soil pollution, etc. were enumerated and the environmental impacts of the industries active in the district. The results showed that 10 industrial units are at very low damage level, 82 units are at low damage level, 204 units are at medium damage level, 96 units at high damage level, and 8 units at very high damage level where area 2 of district 21 is much more polluted. In the second part of the study, the transregional impacts of industries in district 21 on neighboring districts were brought into focus. The results showed that district 18 has been affected by impacts of district 21, more than other districts.

Keywords: Environmental Assessment, District 21, Neighboring districts, IHWP Method

\section{Introduction}

In recent years, urban planners have tried to establish a strong link between planning and societies' public health. In this field, problems such as various diseases, emission of harmful environmental contaminants have led to grow concerns increasingly in the field of increasing environmental contaminants caused by industry development (Forsyth, 2009).

Environment is one of the urban areas' sensitive and vulnerable aspects and expanding urban consumption pattern has led to spread the influx of some urban pollutant resources. The advent of sophisticated technologies and large-scale industries result in incidence of changes in social, economic and environmental aspects (Hosseininejad, 2009: 5). Many theoretical approaches have considered positive the changes resulting from the entry of technology and advanced industry and according to this, industry and technology are considered as development and change factor, but, one of the important issues for the third world countries is the control of its consequences regarding the transfer of large industries and complex technologies rather than is shifted towards the desired direction. In many cases, the entry of industry and technology has had desirable economic results, however beside it, has imposed destructive social and environmental consequences on society. Severe environmental changes caused by industries and technologies have mostly irreparable damages (Tavakol, 2011: 152).

According to estimates of Tehran Air Quality Control Company, damage caused by air pollution in metropolises is 
seven to eight billion Toman. Moreover, studies in 2010 show that 5 thousand deaths are attributed to air pollution. In the meantime, the role of particulate matter less than 10 microns is more than 60 percent (Tebyan News, 2011).

In addition, the establishment of a large number of industrial plants in the area 21 dictates that the issue of environmental pollutions of these productive-economic units are considered so that dedicated lands area to industrial land use is more than any other land use that it means it is 1391.9 hectares (27 percent) of the region area and up to 91.6 square meters per capita. Therefore, maintaining citizens' physical health, protection of environmental resources and decrease in various kinds of pollutions and disturbance of activities would be one of the main axes of environmental issues in this area.

The main aim of this research is evaluating the amount of regional and trans-regional effectiveness of industrial contaminants in area 21 and adjacent areas and its objectives include determining the vulnerability amount of each industry in area 21 and investigating environmental contaminants, in particular air pollution, in adjacent areas.

In the following, several researches in this field will be discussed.

Oketola and Osibanjo (2007) in the study of estimating sectorial pollution load in Lagos by Industrial Pollution Projection System achieved the conclusion that for estimating the cumulative ranking of the pollution load (ton/yr) between all media (i.e. air, land, and water), Chemical and Pharmaceutical (CPH) sectors were the highest polluting sector, followed by Basic Metal (BML), Domestic and Industrial Plastics (DIP), and Food, Beverage and Tobacco (FBT) sectors (Oketola and Osibanjo, 2007:136).

"The analysis of the role and status of urban planning in reducing air pollution (case study: the periphery of fourteen air quality monitoring stations in Tehran) is the topic of Hassan Riazi's master thesis (2012). This research has been performed with the purpose of investigating the role and status of urban planning in improving air quality through analyzing the indicators of city's physical construction and the concentration amount of air pollutants in the periphery of fourteen air quality monitoring stations in Tehran. The results of the research illustrate that access and congestion factors have a meaningful relationship with the concentration amount of $\mathrm{CO}$ and pm10 and the indicators of access to urban centers, access to main roads, the area of urban blocks, access to transportation stations, the congestion of retail units, the area of open spaces, population density, the incorporation of land uses, the area of green spaces and intersections congestion have the most relation with concentration of contaminants. In relation to air pollutants, including primary and secondary pollutants, show that primary pollutants are increased with the approaching high traffic arteries of the city center and are reduced in areas with more green space (Riazi, 2011: 3).

Barughi (1998) in her master's thesis (Urbanism Field) studied "Evaluating the effects of industrial estates development on big cities (case study: industrial estates of Rajai and Salimi in Tabriz)". There are four industrial estates in Tabriz that one of them is specialized (Charmshahr) and others have assigned to establish various types of industrial activities. In this research, the effects of industrial estates development on big cities have been investigated and evaluated. EIA Method has been used to evaluate the environmental effects and consequences of industrial estates (Barughi, 1998: 5).

It is worth mentioning that the main question of the current research is "How much the amount of environmental vulnerability of the area 21 and its adjacent areas in Tehran because of industry?"

\section{City and the Effects of Industrial Activities}

The Industrial Revolution and, besides it, the development of capitalism changed the old balance between economic and non-economic activities and expanded the market field to all sectors and converted all things to interchangeable commodity so that the belief in the absolute power of industry and monetary success overshadowed everything. In the new urban environment, economic, political and social statuses are changed, job insecurity is created for the working class, and competitive market is expanded for labor and selling goods. Factory is one of the important urban units in this period (Momtaz, 2004: 45).

The main elements of the new urban collection are factory and railway and the city itself is converted to a large slum. Factory formed the city's main core and overshadowed all city's aspects. The first factories were constructed in the best urban areas proximity to water sources. In this period, there were not any type of urban management or law to prohibit the establishment of factories in residential areas and prevent polluting the environment (Momtaz, 2009: 43).

The most important of positive and negative effects of industrial activities on adjacent areas as follows: 
Table (1): Classification of industrial activities on adjacent areas

\begin{tabular}{|c|c|}
\hline The field of problems & Problems \\
\hline Environmental & - Existence of a variety of environmental pollution (air pollution, unpleasant odors, smoke, vibration). \\
\hline Physical & - Creating visual disturbance by buildings and facilities of selected industrial activities. \\
\hline Traffic & $\begin{array}{l}\text { - Creating disruptions in the transportation network performance due to trucks traffic and their loading and } \\
\text { unloading materials and products. }\end{array}$ \\
\hline Economical & - Reducing the price of housing in residential functional areas adjacent to the Swan Oil Factory. \\
\hline Social & $\begin{array}{l}\text { - Unwillingness of the residents of residential functional areas (where are adjacent to selected industrial } \\
\text { activities) to participate in planning for reducing the effects of selected industrial activities. } \\
\text { - Living socio-cultural groups with a low level in the adjacent of selected industrial activities. }\end{array}$ \\
\hline Planning & $\begin{array}{l}\text { - The absence of planning mechanism for reducing negative effects of industrial activities within area. } \\
\text { - Lack of coordination and alignment of decision-making entities for pollutants industrial activities. }\end{array}$ \\
\hline Juridical & - Lack of executive warranty for the closedown verdict for pollutants industrial activities. \\
\hline
\end{tabular}

Source: Hoseinnejad, 2009

Industrial pollutions in cities are partner in creating many health problems such as deadly diseases of heart, arterial occlusive, asthma, heart rate and etc. (Marshall et al, 2009). Air pollution is existence of one or more pollutants or combination of them in the exterior or interior atmosphere, in the amount and duration when may cause damage to human, vegetable or animal life or assets unreasonably or interfere with the comfortable enjoyment of life or property (Ejlali, 2007: 23).

Air pollution is not caused by one factor and a series of intertwined issues lead to air pollution. In fact, a part is related to industry, a part caused by cars, another part is dependent on climatic parameters (like wind speed) and some cases are also related to geographical conditions (such as mountains, rivers, slope, etc.) (Musavi, 2010: 10). In relation to air pollution in outdoors, primary and basic pollutants are converted to secondary pollutants by chemical changes that should be recognized their ex-structures (the primary pollutants) to determine them. $\mathrm{CO}$ and NO are the primary pollutants that are produced by cars mostly. $\mathrm{NO}_{2}$ and $\mathrm{O}_{3}$ are secondary pollutants that are created as a result of a complex series of reactions in the atmosphere (Shafipour, 2008: 20). The World Health Organization has specified six pollutants as the main pollutants. These six pollutants are carbon monoxide (CO), nitrogen dioxide (NO2), sulfur dioxide (SO2), lead (pb), ozone (O3) and pollutant particulates which have been diagnosed very harmful to human health (Sarafi et. al, 2009: 10). In the current research, $\mathrm{NO}_{2}, \mathrm{CO}_{2}, \mathrm{PM} 2.5$ and $\mathrm{Pm} 10$ have been considered.

\section{Introducing the Case Study}

Tehran's area 21 is expanded as triangular in the end part of Tehran's west along the roads of Tehran-Karaj to after the Dilemma of the Stone Inn. This area is has been limited to Tehran-Karaj highway from the north, old road of TehranKaraj from the south, Kan Watercourse from the east and along the north-south of longitude $51^{\circ}$ (between Tehran-Karaj old road and highway) from the west. Moreover, this area is adjacent to area 22 from the north, area 5,9 and 18 from the east, Karaj from the west and Tehran's south greenbelt and Shahriar from the south.

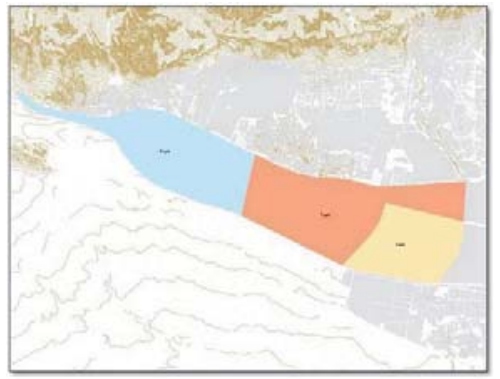

Figure (1): The position of Tehran's area 21 


\section{Calculating the Vulnerability Amount of the Area Study Against Industry Pollution}

Estimating the capability of vulnerability has been surrounded by ambiguities and uncertainties because calculating the amount of vulnerability, using Boolean Model, does not allow to vulnerability criteria that becomes membership as a continuous spectrum. For this reason, Inversion Hierarchical Weight Process (IHWP) Model has been used (Shie et. al, 2010: 36).

The IHWP Model is a combination of Fuzzy Logic and Analytical Hierarchy Process (AHP) that the first time, Dr. Kiumars Habibi has used from this method in his PhD thesis at the Tehran University and also Sajad Abazarlou has written the mathematical functions of this method in his master thesis at Islamic Azad University Central Tehran Branch (Abazarlou, 2013: 131).

\subsection{First step: Presentation of selected indices to identify vulnerable zones against industrial pollution}

- Water pollution: Water pollution is increase in the amount of every reagent including chemical, physical or biological that leads to changes in its properties and fundamental role in special consumptions (Anabestani and Ghorbani, 2011).

- Air pollution: Air pollution is the existence of one or more pollutants or combination of them in the exterior or interior atmosphere, in the amount and duration when may cause damage to human, vegetable or animal life or assets unreasonably or interfere with the comfortable enjoyment of life or property (Vark et. al, 2009). With the growth in technology and exiting fixed and industrial pollutants resources from cities, fixed pollution resources in the industrial sector has been introduced as the main challenge for the pollution of Metropolises more than ever (Ejlali, 2007).

- Soil pollution: Soil pollution is the existence, distribution or mixing one or several external material with soil and with the amount and duration that its physical, chemical and biological qualities are harmful for humans and other living things. Factors that cause soil pollution as a result of human activities, for example, include: pouring toxic materials such as all kinds of solvents colored materials and detergents extend land and soil pollutions.

- Noise Pollution: Noise has the most emission among all occupational pollutants and there is almost in every industry. Noise not only leads to disease, but also, Hurt and indignation of person. Interference in conversation and preventing from hearing warning sounds cause disasters and reduction in production (Riazi, 2012).

- Congestion of hazardous industrial centers: The purpose of the hazardous industrial centers is the centers in which there is the possibility of ignition, explosive and emissions of toxic material and concentration of these centers would cause environmental hazards intrinsically.

- Access to green spaces: Urban green spaces have an important role in the maintenance and balance of urban environment and mitigation of air pollution. Pollutions caused by industry and technology have been converted cities to hell for its inhabitants (Azizi, 2001).

- Privacy of residential areas: In the establishment of industries, the privacy of residential areas must be observed for the comfort and safety of residents around it which this would cause reduce the environmental impacts of industries.

- Privacy of military and police areas: Military and police areas are one of the most important areas in cities that their privacy must be considered and observed in the establishment of industries.

\subsection{Second step: Presenting strategies of Inversion Hierarchical Weight Process (IHWP)}

- Determination of the importance and rank of data

After identifying case layers based on the importance of each factor in vulnerability of pollutions caused by industries, selected Indicators are ranked on the basis of Delphi Method (experts' and specialists' opinions). Then, the reverse of each layer rank is considered as the weight of that layer in the IHWP Model. In the Delphi Model, eight mentioned indicators are ranked in different classes with different degrees of its importance according to experts' opinions. According to this, the most important indicator allocates number 10 and the least important indicator allocates number 0 to itself in terms of the vulnerability importance caused by pollution (Habibi et. al, 2009: 25).

- Assumptions of weighting 
In this step, 8 indicators of the research are investigated with considering the assumptions. Such as the indicator of air pollution is more important than other indicators regarding its effects that are more than others and the more air pollution, the more it would has negative environmental effects and the more industry access to green spaces, the more the possibility of pollution would be reduced.

Therefore, it is obvious that the more the air, water, soil, noise, pollution, the congestion of hazardous industrial centers and the less industry access to green spaces and the privacy of residential areas and the privacy of military and police areas, the more the negative environmental effects. In Table (2), the assumptions of the research have been reviewed.

Table (2): Average and the importance of indicators leading Delphi questionnaire

\begin{tabular}{|l|c|l|}
\hline Indicator & Ranking & Assumptions of weighting \\
\hline Water Pollution & 3 & The more pollution = The more vulnerability \\
\hline Air Pollution & 1 & The more pollution = The more vulnerability \\
\hline Soil Pollution & 4 & The more pollution = The more vulnerability \\
\hline Noise Pollution & 2 & The more pollution = The more vulnerability \\
\hline Congestion of hazardous industrial centers & 6 & The less access = The more vulnerability \\
\hline Access to green spaces & 5 & The less privacy = The more vulnerability \\
\hline Privacy of residential areas & 7 & The less privacy = The more vulnerability \\
\hline Privacy of military and police areas & 8 & The more congestion = The more vulnerability \\
\hline
\end{tabular}

Source: Research findings, 2016

\subsection{Calculating the scores of selected layers by using IHWP Method}

In the following table, selected indicators have been shown along with the number of classes for each indicator and their scores.

$$
\begin{aligned}
& X=D / N \\
& X=\text { Primary score of each indicator } \\
& D=\text { Scores obtained from the Delphi } \\
& N=\text { The number of classes for each indicator } \\
& J=D-(N-i) X
\end{aligned}
$$

\begin{tabular}{|c|c|c|c|c|c|c|c|c|}
\hline Indicator & $\begin{array}{c}\text { Ranking based } \\
\text { on Delphi }\end{array}$ & \begin{tabular}{|l|} 
Reverse \\
Ranking
\end{tabular} & $\begin{array}{c}\text { The number of classes } \\
\text { for each indicator }\end{array}$ & \multicolumn{5}{|c|}{ The weight in the IHWP Model } \\
\hline \multirow[b]{2}{*}{ Air Pollution } & 1 & 8 & 2 & 4 & 8 & & & \\
\hline & & & & It has & $\begin{array}{l}\text { It does not } \\
\text { have }\end{array}$ & & & \\
\hline \multirow[b]{2}{*}{ Noise Pollution } & 2 & 7 & 2 & 3.5 & 7 & & & \\
\hline & & & & It has & $\begin{array}{l}\text { It does not } \\
\text { have }\end{array}$ & & & \\
\hline \multirow[b]{2}{*}{ Water Pollution } & 3 & 6 & 2 & 3 & 6 & & & \\
\hline & & & & It has & $\begin{array}{l}\text { It does not } \\
\text { have }\end{array}$ & & & \\
\hline \multirow[b]{2}{*}{ Soil Pollution } & 4 & 5 & 2 & 2.5 & 5 & & & \\
\hline & & & & It has & $\begin{array}{l}\text { It does not } \\
\text { have }\end{array}$ & & & \\
\hline \multirow[b]{2}{*}{ Access to open space } & 5 & 4 & 5 & 0.8 & 1.6 & 2.4 & 3.2 & 4 \\
\hline & & & & Less than $200 \mathrm{~m}$ & 200 to $400 \mathrm{~m}$ & $\begin{array}{l}400 \text { to } \\
600 \mathrm{~m}\end{array}$ & $\begin{array}{l}600 \text { to } \\
1000 \mathrm{~m}\end{array}$ & $\begin{array}{l}\text { More than } \\
1000 \mathrm{~m}\end{array}$ \\
\hline \multirow{2}{*}{$\begin{array}{l}\text { Congestion of hazardous } \\
\text { industrial centers }\end{array}$} & 6 & 3 & 5 & 0.6 & 1.2 & 1.8 & 2.4 & 3 \\
\hline & & & & Very little & Little & Medium & Much & Very much \\
\hline \multirow[b]{2}{*}{ Privacy of residential areas } & 7 & 2 & 5 & 0.4 & 0.8 & 1.2 & 1.6 & 2 \\
\hline & & & & Less than $200 \mathrm{~m}$ & 200 to $400 \mathrm{~m}$ & $\begin{array}{c}400 \text { to } 600 \\
\mathrm{~m}\end{array}$ & $\begin{array}{l}600 \text { to } \\
1000 \mathrm{~m}\end{array}$ & $\begin{array}{l}\text { More than } \\
1000 \mathrm{~m}\end{array}$ \\
\hline \multirow{2}{*}{$\begin{array}{l}\text { Privacy of military and police } \\
\text { areas }\end{array}$} & 8 & 1 & 5 & 0.2 & 0.4 & 0.6 & 0.8 & 1 \\
\hline & & & & Less than $100 \mathrm{~m}$ & 100 to $300 \mathrm{~m}$ & $\begin{array}{c}300 \text { to } 600 \\
\mathrm{~m}\end{array}$ & $\begin{array}{c}600 \text { to } 900 \\
\mathrm{~m}\end{array}$ & $\begin{array}{l}\text { More than } \\
900 \mathrm{~m}\end{array}$ \\
\hline
\end{tabular}

Table (3): The weight of classified indicators for determining the area's vulnerability against industries pollution

Source: The author, 2016 
- Third step: Combining the maps: Using the tools of Raster Calculate, scores columns related to every one of the created information layers are added together.

- Providing the final vulnerability map of the area: In this step, final map has been produced with data classification in five distinct categories (including very low, low, medium, high and very high) in terms of area's vulnerability against pollution.

The map of area's industrial pollution damage is divided to 5 sections. $2.29 \%$ of the industries in the area have very low pollution, $20.93 \%$ have low pollution, $51.63 \%$ have medium pollution, $23.71 \%$ have high pollution and $1.43 \%$ have very high pollution.

Table (4): The amount of the area's vulnerability against industries pollution

\begin{tabular}{|l|c|}
\hline Zoning & Percentage \\
\hline very low pollution & 2.29 \\
\hline low pollution & 20.93 \\
\hline medium pollution & 51.63 \\
\hline high pollution & 23.71 \\
\hline very high pollution & 1.43 \\
\hline Sum & 100 \\
\hline
\end{tabular}

Source: Research findings, 2016

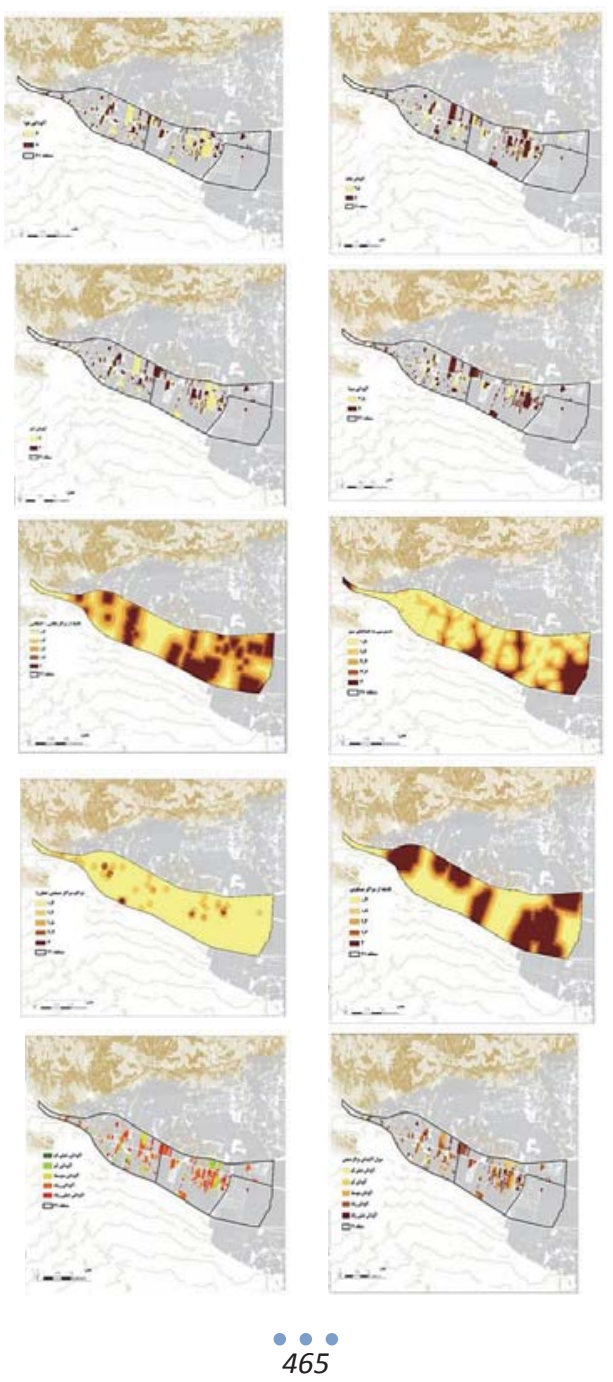




\section{Suggestions}

- Making some changes in the characteristics of urban construction such as residential and population density in the area.

- Creating open spaces and the use of vegetation cover in the area centers and areas where a high density of industry have as the area's respiratory lungs.

- Observing residential centers privacy in new site selections.

- Hazardous industries should not be located in the privacy of each other.

- Vital industrial centers should have a proper and safe distinct from hazardous sites as possible as.

- Creating the legal context and foundation to observe environmental considerations in the issue of establishing and constructing industries, in dominant laws expressly and specifically.

- Justifying the role and position of environmental considerations in construction and establishment of industries for responsibilities, planners and national policymakers.

- Approving and reviewing criteria and standards of establishing industries with the attention of representatives of the Industry Ministry, environment organization, the Ministry of Agriculture, the Ministry of Interior.

- Providing the administrative regulations of establishing and constructing industries with a focus on observing environmental considerations in collaboration with the Industry Ministry, environment organization, the Ministry of Agriculture, the Ministry of Interior.

- Enforcing the various governmental, public and private departments to observe environmental considerations in construction and establishment time of industries through legal prohibition, judicial approach and preventing their activities.

\section{References}

Abazarloo, S. (2013) Assessment of city vulnerability with passive defense approach using fuzzy logic (Master of thesis), Islamic azad university Centeral Tehran branch, Supervisor: Habibi , K.

Anabestani , A , A \& Ghorbani , M. (2011) Master plan to reduce pollution of the city's water sabzevar, water and soil conservation researches (sciences of agricultural and natural resources), 18(4), 225-232.

Azizi , M ,M.(2001) Density in the urbanization , Tehran : Tehran university press.

Baroghi bonab, F. (1998), Survey influence of development Industrial town on big town, case study:rajaei and salimi Industrial town :Tabriz's (Master of thesis), shahid beheshti university.

Ejlali, F. (2007) Air pollution, Karaj: Agriculture education press.

Forsyth, A. Schmid, T. Sallis, J. et al. (2009). Linking Objectively Measured Physical activity with objectively measured urban form: finding form SMARTARQ. American Journal of Preventative Medicine 28 (282), 117-125

Habibi, K. et al. (2009), urban safety and GIS, Imam Hossein university of Tehran.

Hosseini nezhad, F, S. (2009) Planning to analyze the evil effect of the industrial activity on residential areas function, Case Study: 16 region in Tehran (Master of thesis), shahid beheshti university.

Marshal, J., Brauer, M., Frank, L., L., (2009). Healthy Neighbohoods: Walkability and Air Pollution Enviromental Health Prespectives, number 11.

Marshal, J., Brauer, M., Frank, L., L., (2009). Healthy Neighbohoods: Walkability and Air Pollution Enviromental Health Prespectives, number 11.

Mousavi, M. (2010) Organization of industry and habitation in urban areas, Tehran: Parham role press.

Mumtaz, F. (2004) Sociology in the city, (3th ed) Tehran: publishing stock company press.

Oketola .A.A \& Osibanjo .O, (2007), "Estimating sectoral pollution load in Lagos by Industrial Pollution Projection System (IPPS)", Journal of Science of the Total Environment, No. 377, pp125-141.

Sarfi, A. et al. (2009) Prioritizing of social , economic and environmental injures as a result of the existence industrial places in side of the urban settlement, case study : citizens of 21 region in Tehran, Conference of industry and habitation .

Riazi , H. (2013) Analysis the role of urban planning in reducing air pollution (Master of thesis), Supervisor : Zebardast , E. Tehran university.

Tavakol, M. (2011), Sociology of technology, Tehran: sociologists press .

TBEAN's news site:http//tebyannews.com/article/22743,reference in the history of the 22/6/2013.

Varak , C . et al.. (2009) Air pollution (origin and control it). (Nadafi , K et al), (1th ed ) Tehran : Nasr press. 